\title{
Electronic sensors and biosensor used for automation in the food industry
}

\section{Priyanka Handa and Bhupinder Singh}

Received : $03.07 .2020 ;$ Accepted : 27.09 .2020

See end of the Paper for authors' affiliation

Correspondence to :

Bhupinder Singh

Department of Food Technology, Ch. Devi Lal State Institute of Engineering and Technology, Panniwala Mota, Sirsa (Haryana) India

Email: bhupimander@rediff mail.com
- ABSTRACT : The current health pandemic and crisis has added a mountain of challenges across the food and beverage industry, as consumer buying patterns are changing and both production of goods and other business operations have been disrupted. Human touch should be minimized to reduce such kind of infections. So automation of food industry should be increased. The food industry has traditionally lagged behind other industries in adopting new technology, and plant automation is no exception. However, rapid advances in computer technology and heightened expectations of consumers and regulatory agencies for improved food quality and safety have forced the food industry to consider automation of most manufacturing processes. Though the food industry presents many unique challenges to complete automation, the industry has been successful in putting many automatic processes into place. Sensors and controllers are electronic devices and are the main backbone for the automation of food industry. In this paper some important electronic sensors and biosensors used for food automation are described.

- KEY WORDS : Biosensors, Automation, Electronic sensors, Controllers

- HOW TO CITE THIS PAPER : Handa, Priyanka and Singh, Bhupinder (2020). Electronic sensors and biosensor used for automation in the food industry. Internat. J. Agric. Engg., 13(2) : 276-282, DOI: 10.15740/HAS/IJAE/13.2/276-282. Copyright@2020: Hind Agri-Horticultural Society. 